\title{
Utilização de filme de quitosana para o controle de aflatoxinas em amendoim
}

\author{
Juliana Fonseca Moreira da Silva ('); Guilherme Prado ('); Jovita Eugênia Gazzinelli Cruz Madeira (2); \\ Marize Silva Oliveira ( ${ }^{2}$ ); André Augusto Gomes Faraco ( $\left.{ }^{3}\right)$; Camilla Martins Malta ('); \\ Jacques Robert Nicoli (3); Raphael Sanzio Pimenta $\left({ }^{1 *}\right)$
}

(') Universidade Federal do Tocantins (UFT), Laboratório de Microbiologia Geral e Aplicada, Avenida NS 15, 109 Norte, Plano Diretor Norte, 77001-090 Palmas (TO), Brasil.

(2) Fundação Ezequiel Dias (FUNED), Núcleo de Micologia e Micotoxinas, Rua Conde Pereira Carneiro, 80, 30510-010 Belo Horizonte (MG), Brasil.

(3) Universidade Federal de Minas Gerais (UFMG), Instituto de Ciências Biológicas, Departamento de Microbiologia, Av. Antônio Carlos 6627, J4-171, 30161-970 Belo Horizonte (MG), Brasil.

(*) Autor correspondente: biorapha@yahoo.com.br

Recebido: 18/mar./2015; Aceito: 25/maio/2015

\begin{abstract}
Resumo
Neste estudo, verificou-se a utilização de um filme de quitosana para o controle do crescimento e produção de aflatoxinas por A. parasiticus em amendoim. Os filmes foram aplicados sobre os grãos por meio de duas metodologias (aspersão e imersão). Os grãos recobertos foram inoculados com $2,5 \mathrm{ml}$ de uma suspensão contendo $1,0 \times 10^{6}$ esporos/ml e incubados a $25{ }^{\circ} \mathrm{C}$ por 7 dias. A concentração de aflatoxinas foi determinada por cromatografia em camada delgada, utilizando a técnica de densitometria. A verificação da inibição do crescimento fúngico foi realizada por meio da inoculação do patógeno em placas de Petri contendo GYEP suplementado com quitosana a 2\% e incubadas por 7 dias a $25^{\circ} \mathrm{C}$. Após incubação, o diâmetro da colônia do patógeno foi estimado e comparado com o controle. Todos os testes foram realizados com cinco repetições. Para a verificação de alterações morfológicas, uma suspensão de esporos ou hifas incubados na presença de quitosana foi submetida à microscopia eletrônica de varredura. Foi observado que tanto o método de imersão quanto o de aspersão reduziram a produção de aflatoxina significativamente, $84,3 \%$ e $86,7 \%$ respectivamente. A presença de quitosana no meio de cultura reduziu o diâmetro das colônias e promoveu modificações morfológicas nos esporos de A. parasiticus. Com esse procedimento foi verificado que a utilização de quitosana a 2\% na forma de filme, principalmente por aspersão, pode reduzir a concentração de esporos e aflatoxinas de A. parasiticus em amendoim, o que confere a essa substância uma grande perspectiva de utilização no controle de fungos aflatoxigênicos.
\end{abstract}

Palavras-chave: Arachis hypogaea, Aspergillus parasiticus, micotoxinas, pós-colheita, substância GRAS.

\section{Use of chitosan film to control aflatoxins in peanuts}

\begin{abstract}
In this study, we evaluate the utilization on chitosan film to control the growth and aflatoxin production by A. parasiticus in peanut. The films were inoculated over the grains by aspersion or immersion methods. The chitosan coated grains were inoculated with $2.5 \mathrm{ml}$ solution with $1.0 \times 10^{6}$ spores $/ \mathrm{ml}$ and incubated at $25^{\circ} \mathrm{C}$ for 7 days. The aflatoxin concentration was estimated by thin layer chromatography and densitometry. The fungus growth inhibition was observed by pathogen inoculation in Petri dishes with GYEP media plus $2 \%$ chitosan and incubated by 7 days at $25^{\circ} \mathrm{C}$. After incubation the colony diameter was measured and compared with the control. All assays were repeated five times. To verify morphological alterations, a spore/hypha suspension was incubated in media with chitosan and observed in scanning electron microscopy.Both methods (immersion and aspersion) were able to reduce the aflatoxin production significantly, $84.3 \%$ and $86.7 \%$, respectively. The chitosan reduced the colonies diameters and promoted morphological alterations in A. parasiticus spores. With this, was observed that a $2 \%$ chitosan film, specially inoculated by aspersion, can to reduce A. parasiticus spores and aflatoxins concentrations in peanuts. This characteristic gives to this substance an excellent perspective to be used in aflatoxigenic fungi control.
\end{abstract}

Key words: Arachis hypogaea, Aspergillus parasiticus, mycotoxins, postharvest, GRAS substances. 


\section{INTRODUÇÃO}

O amendoim é um grão que possui altos índices de proteínas e óleos que, aliado ao seu agradável sabor, o torna muito consumido por adultos e crianças nas mais diversas formas, quer seja in natura, torrado, em doces, confeitos ou, ainda, em pratos da culinária de diversos países. Este alimento é muito susceptível à contaminação por micotoxinas (aflatoxinas), podendo esta ocorrer praticamente em todas as fases das várias etapas da sua cadeia produtiva (Viegas \& Rossetto, 2006).

As micotoxinas são metabólitos tóxicos produzidos por algumas espécies de fungos. Uma das micotoxinas de maior significado em saúde pública e na agricultura são as aflatoxinas, produzidas com maior frequência pelas espécies Aspergillus flavus e $A$. parasiticus. Estas toxinas são extremamente carcinogênicas e teratogênicas (Klich, 2007).

Nos últimos anos, o consumidor tem aumentado o interesse por alimentos seguros, com isso a procura por metodologias capazes de substituir total ou parcialmente o uso de agrotóxicos na agricultura tem aumentado. Por possuir aceitação mundial, as substâncias "GRAS" (Generally Regarded As Safe) tornaram-se grandes aliadas na manutenção da qualidade dos alimentos. Substâncias como a quitosana têm sido estudadas por inibirem o crescimento de vários micro-organismos (Campana-Filho et al., 2007; Cerqueira et al., 2011).

A quitosana, um polímero policatiônico $ß-1,4$ ligado à D-glucosamina, é uma poliamina linear, que pode ser obtida pela desacetilação alcalina da quitina ( $\mathrm{N}$ - acetilglucosamina). A quitina é o biopolimero mais abundante na natureza, depois da celulose, e pode ser encontrada em abundância no exoesqueleto de crustáceos, como camarão, siri, caranguejo, lagosta e de plantas como as algas marinhas (Botelho et al., 2010; Moura et al., 2006).

A quitosana tem um grande potencial para aplicações devido a uma variedade de propriedades tais como, biodegradabilidade, biocompatibilidade, atividade antimicrobiana e atoxicidade. Os filmes à base de quitosana têm-se demonstrado eficazes na conservação de diversos alimentos (Campana-Filho et al., 2007; Cerqueira et al., 2011; Cia et al., 2010; Mali et al., 2010).

Os filmes comestíveis podem ser importantes na extensão da vida útil de alimentos, funcionando como barreira de proteção contra a invasão de micro-organismos patogênicos e garantindo sua segurança microbiológica (Mali et al., 2010).

Esta pesquisa visou à incorporação de um filme comestível à base de quitosana para reduzir o crescimento e produção de esporos e aflatoxinas por $A$. parasiticus em amendoim. Com isso, foi proposta uma alternativa eficiente e viável para a manutenção da qualidade e segurança microbiológica e toxicológica do amendoim.

\section{MATERIAL E MÉTODOS}

\section{Obtenção das sementes}

Foram utilizados grãos de amendoim autoclavados, cultivar IAC Caiapó. Os grãos apresentavam alto teor de óleo, tamanho médio, cor castanha e isentos de aflatoxinas. Para a realização dos experimentos foram utilizados grãos colhidos na safra de 2009/2010.

\section{Obtenção do fitopatógeno}

Foi utilizada a linhagem de $A$. parasiticus IMI 242695 proveniente do International Mycological Institute, Inglaterra, isolada de produtos alimentícios e produtora de aflatoxinas $\left(B_{1}, B_{2}, G_{1}\right.$ e $\left.G_{2}\right)$. Este micro-organismo encontra-se depositado na coleção de cultura de fungos do Laboratório de Micologia da Fundação Ezequiel Dias (FUNED).

\section{Obtenção da quitosana}

A quitosana utilizada para a elaboração do filme foi adquirida da Sigma-Aldrich ${ }^{\circledR}$ com $85 \%$ de desacetilaçáo.

\section{Preparo das soluções de quitosana}

As soluçôes de quitosana foram preparadas por meio da dissolução da quitosana $(0,5,1,0$ e 2,0 g) em uma solução de ácido clorídrico $(\mathrm{HCl})$ a $2 \% \mathrm{v} / \mathrm{v}$ até atingir o volume final de $100 \mathrm{ml}$; após a completa dissolução, as soluçôes foram filtradas e armazenadas sob refrigeração.

\section{Preparação do fitopatógeno}

A linhagem de $A$. parasiticus foi inoculada em placa de Petri contendo o meio de cultura Czapek (nitrato de sódio $4 \%$, cloreto de potássio $1 \%$, sulfato de magnésio $7 \mathrm{H} 2 \mathrm{O} 1 \%$, sulfato ferroso $7 \mathrm{H} 2 \mathrm{O} 0,02 \%$, fosfato de potássio dibásico $2 \%$, sacarose $3 \%$, sulfato de zinco $7 \mathrm{H} 2 \mathrm{O}$ a $1 \%$, sulfato de cobre a $0,5 \%$, ágar $2 \%$ ) e incubada por 7 dias a $25^{\circ} \mathrm{C}$. Após esporulaçáo, uma alçada de esporos foi transferida para tubo de ensaio, contendo $1,5 \mathrm{ml}$ de Tween $80 \%$ a $0,1 \%$, com posterior agitação por 1 minuto para dispersão dos esporos. Em seguida, foram transferidos, $200 \mu \mathrm{L}$ dessa suspensão para um frasco Erlenmeyer de $250 \mathrm{ml}$, contendo $25 \mathrm{ml}$ do meio GYEP (glicose $2 \%$, extrato de levedura $0,3 \%$ e peptona $1 \%$ ) e em seguida incubado a $25^{\circ} \mathrm{C}$ por 7 dias para nova esporulação.

Após esse tempo, foram adicionados $20 \mathrm{ml}$ de Tween $80 \%$ a $0,1 \%$ em cada um dos frascos e 10 pérolas de vidro, agitou-se vagarosamente e transferiu-se o sobrenadante para outro Erlenmeyer de $250 \mathrm{ml}$ esterilizado. O número de esporos $/ \mathrm{ml}$ da suspensáo foi calculado com o auxílio de uma 
câmara de Neubauer e ajustado para $1,0 \times 10^{6}$ esporos $/ \mathrm{ml} \mathrm{em}$ $50 \mathrm{ml}$ de Tween $80 \%$ a $0,1 \%$ (Prado et al., 2011).

\section{Verificação da inibição do crescimento de} A. parasiticus

Para verificar a inibiçáo do crescimento de $A$. parasiticus por quitosana in vitro, placas controle (contendo GYEP sem suplemento) e as placas testes (GYEP suplementadas com as soluçóes de quitosana) foram incubadas por 7 dias a $25^{\circ} \mathrm{C}$. A obtenção dos esporos foi realizada através do cultivo do $A$. parasiticus em placa de Petri contendo o meio de cultura Czapek. Após esporulaçáo, uma alçada de esporos foi transferida para tubo de ensaio, contendo $15 \mathrm{ml} \mathrm{de}$ Tween $80 \%$ a $0,1 \%$ com posterior agitação em vórtex para dispersão dos esporos.

A concentração de esporos foi obtida com o auxílio de uma câmara de Neubauer e em seguida ajustada para $1,0 \times 10^{6}$ esporos $/ \mathrm{ml}$. Em seguida inoculou-se três "spots", contendo $10 \mu \mathrm{L}$ da suspensão, nas placas controle e nas placas testes (meio cultura GYEP suplementados com quitosana $0,5 \%, 1,0 \%$ e $2,0 \%)$. Em seguida, as placas foram incubadas a $25^{\circ} \mathrm{C}$ por 7 dias. Após a incubação, o diâmetro da colônia do patógeno foi medido com auxílio de um paquímetro digital (Jomarca ${ }^{\circledR}$ ) e comparado com o diâmetro observado na cultura controle. Todos os testes foram realizados com cinco repetiçôes.

\section{Verificação de alterações morfológicas do} A. parasiticus

Para verificar a presença de alteraçôes morfológicas nas estruturas reprodutivas de $A$. parasiticus, foram realizados dois procedimentos com as placas controle e as placas teste do procedimento acima descrito. Para o primeiro utilizou-se uma suspensão a partir de uma alçada de esporos do crescimento do fungo que posteriormente foi transferido para tubo de ensaio, contendo $1,0 \mathrm{ml}$ de Tween $80 \%$ a $0,1 \%$ e submetido à agitação em vórtex para dispersão dos esporos. $\mathrm{O}$ outro procedimento foi realizado com a retirada de fragmentos de hifas, que foram imersos em Tween $80 \%$ a $0,1 \%$ e encaminhados para a realização da microscopia eletrônica de varredura, conforme metodologia recomendada pelo CM/UFMG.

Após a realização da suspensão e da retirada dos fragmentos de hifas, $10 \mu \mathrm{l}$ da suspensão e fragmentos das hifas foram inoculados em uma lamínula pré-tratada com Poli-L-Lisina e deixados à temperatura ambiente (dentro do fluxo laminar) até sua completa secagem.

Posteriormente, as lamínulas foram fixadas em glutaraldeído $2,5 \%$, em tampão cacodilato $0,1 \mathrm{M}$ por no mínimo $1 \mathrm{~h}$, após esse período o fixador foi removido e as amostras lavadas três vezes por 10 minutos em tampáo cacodilato $0,1 \mathrm{M}$.
As amostras foram novamente imersas e fixadas por 1 hora com tetróxido de ósmio $1 \%$, depois lavadas por três vezes (10 min.) em tampão cacodilato $0,1 \mathrm{M}$. Após esse processo, as amostras foram imersas em ácido tânico $1 \%$ em tampão cacodilato $0,1 \mathrm{M}$ por 20 minutos, em seguida as amostras foram imersas novamente no fixador tetróxido de ósmio $1 \%$, e lavadas por três vezes (10 min.) em água destilada.

Após essa etapa, as amostras foram desidratadas em soluçáo crescente de Álcool etílico 35\%, 50\% e 95\% (por 10 min.) e em $100 \%$ (três vezes por $10 \mathrm{~min}$.), após a desidratação as amostras foram secas no ponto crítico de $\mathrm{CO}_{2}$. Em seguida, as amostras foram montadas nos "stub" usando cola de carbono, posicionando a lamínula com as células aderidas sobre a fita de carbono e metalizadas com ouro $(3 \mathrm{~mm}$ de espessura). As imagens digitais foram capturadas no microscópio eletrônico de varredura JEOL JSM-6360LV.

\section{Elaboração do filme de quitosana por imersão}

Os amendoins foram imersos na solução de quitosana a $2 \%$, previamente preparada e, logo em seguida, colocados para secar em jato de ar (temperatura entre 35 e $40{ }^{\circ} \mathrm{C}$ ). Para o controle negativo, os amendoins foram imersos em água destilada estéril.

\section{Elaboração do filme de quitosana por aspersão}

Os grãos de amendoim foram aspergidos com a solução de quitosana, previamente preparada. Para o controle negativo, a água destilada estéril foi aspergida sobre os amendoins.

A aspersão foi realizada através de um dispositivo de pressão positiva que insuflou o ar na solução a ser aplicada, deslocando a soluçáo de um recipiente para outro onde se encontrava os amendoins. Após o insuflamento de cada uma das camadas, os amendoins foram secos com jatos de ar (temperatura entre 35 e $40{ }^{\circ} \mathrm{C}$ ). Esse insuflamento foi repetido até atingir 200 camadas de revestimento em cada grupo de amendoim.

\section{Verificação da redução da produção aflatoxina}

As sementes de amendoim (15 g.), in natura, foram previamente autoclavadas a $121^{\circ} \mathrm{C}$ por 15 minutos e distribuídas em dois experimentos com três grupos cada:

\section{Experimento 1 - imersão}

Grupo 1 = (controle positivo) foi inoculado com $2,5 \mathrm{ml}$ da suspensão com $1,0 \times 10^{6}$ esporos $/ \mathrm{ml}$ do fungo aflatoxigênico nos amendoins imersos em água destilada estéril. 
Grupo 2 = (ensaio) foi inoculado com $2,5 \mathrm{ml}$ da suspensão com $1,0 \times 10^{6}$ esporos $/ \mathrm{ml}$ do fungo aflatoxigênico nos amendoins previamente imersos em solução de quitosana a $2 \%$;

Grupo 3= (controle negativo) foi inoculado com 2,5 ml de Tween $80 \%$ a $0,1 \%$ nos amendoins previamente imersos em soluçáo de quitosana a $2 \%$.

\section{Experimento 2 - Aspersão}

Grupo 1 = (controle positivo) foi inoculado com $2,5 \mathrm{ml}$ da suspensão com $1,0 \times 10^{6}$ esporos $/ \mathrm{ml}$ do fungo aflatoxigênico nos amendoins aspergidos com água destilada estéril.

Grupo 2 = (ensaio) foi inoculado com $2,5 \mathrm{ml} \mathrm{da}$ suspensão com $1,0 \times 10^{6}$ esporos $/ \mathrm{ml}$ do fungo aflatoxigênico nos amendoins previamente aspergidos com a solução de quitosana a $2 \%$;

Grupo 3= (controle negativo) foi inoculado com 2,5 ml de Tween $80 \%$ a $0,1 \%$ nos amendoins previamente aspergidos com a soluçáo de quitosana a $2 \%$.

Em seguida, todos os grupos foram incubados a $25^{\circ} \mathrm{C}$ durante 7 dias. Os experimentos foram realizados com cinco repetiçóes de cada grupo.

\section{Determinação de aflatoxinas}

A quantificação das aflatoxinas foi realizada por cromatografia em camada delgada, utilizando a técnica de comparação com padrốes por densitometria (Valente Soares \& Rodriguez-Amaya, 1989).

\section{Análise estatística}

O delineamento experimental utilizado para avaliar a reduçáo da produção de aflatoxina foi inteiramente casualizado, com cinco repetiçóes e três tratamentos e dois tipos de revestimentos (imersão e aspersão). Os tratamentos foram:

Controle positivo 1: Amendoins imersos em água destilada estéril, amendoins imersos em soluçáo de quitosana a 2\%; controle positivo 2: Amendoins aspergidos com água destilada estéril, amendoins aspergidos com solução de quitosana a $2 \%$.

Foi realizado o teste $\mathrm{F}(\mathrm{p}<0,05)$. As médias foram comparadas pelo teste de Tukey $(\mathrm{p}<0,05)$. Os dados foram submetidos ao teste de normalidade de Kolmogorov-Smirnov, com o intuito de verificar a instabilidade de resposta entre as médias dos grupos experimentais.

O delineamento experimental utilizado para a determinação da influência das substâncias "GRAS" sobre o crescimento do A. parasiticus foi inteiramente casualizado, com cinco repetições e quatro tratamentos. Os tratamentos foram:

Crescimento do controle positivo $A$. parasiticus em meio de cultura sem suplemento; e o crescimento do fitopatógeno em meios suplementados com quitosana a $0,5 \%$, quitosana a $1 \%$, quitosana a $2 \%$.

Foi realizado o teste $\mathrm{F}(\mathrm{p}<0,05)$. As médias foram comparadas pelo teste de Tukey $(\mathrm{p}<0,05)$. Os dados foram submetidos ao teste de normalidade de Kolmogorov-Smirnov, com o intuito de verificar a instabilidade de resposta entre as médias dos grupos experimentais. O programa estatístico utilizado foi o Sisvar versão 5.3, UFLA.

\section{RESULTADOS E DISCUSSÕES}

Ao observar a média do diâmetro da colônia de $A$. parasiticus, em meio suplementados com quitosana a $0,5 \%, 1,0 \%$ e $2,0 \%$, verificou-se que ocorreu uma diferença significativa entre os diâmetros em todas as concentraçóes avaliadas, quando comparados ao controle positivo. Quando comparados os crescimentos fúngicos entre as diferentes concentrações de quitosana verificou-se que a maior concentração testada foi estatisticamente mais eficiente que as demais.

A média do diâmetro do crescimento da colônia foi gradativamente reduzida à medida que se elevava a concentração de quitosana (Tabela 1). As médias dos tratamentos sofreram transformaçôes logarítmicas, uma vez que foi observada instabilidade da resposta, isto é, aumento da proporcionalidade entre as médias dos grupos experimentais e seus respectivos desvios padrôes, configurando a não conformidade com os pré-requisitos exigidos para a análise de variância.

Nos experimentos in vitro, a germinação do $A$. parasiticus foi lenta, as hifas se apresentavam de forma agregada, excessivamente ramificada, intumescidas e com comprimento reduzido dos conidióforos na presença de meio de cultura GYEP suplementado com quitosana ( $0,5 \%$ e $1 \%)$, quando comparado com a germinação e o crescimento do fitopatógeno em meio de cultura sem suplementação. No experimento onde a concentração de quitosana foi maior (2\%), as alteraçóes morfológicas das hifas foram mais facilmente visualizadas quando comparadas aos resultados observados no controle (Figuras 1a,b, Figuras 2a,b, Figuras 3a,b e Figuras 4a,b).

As eletromicrografias obtidas mostraram que os conídios resultantes a partir do meio de cultura GYEP suplementado com quitosana $(0,5 \%$ e $1 \%)$ náo apresentaram diferenças

Tabela 1. Médias do diâmetro da colônia ( $\mathrm{mm}$ ) de $A$. parasiticus em meio suplementados com quitosana $0,5 \%, 1,0 \%$ e $2 \%$

\begin{tabular}{|c|c|c|}
\hline Ensaios & Média & Desvio padrão \\
\hline Controle A. parasiticus & $38,6 \mathrm{~A}$ & 0,9 \\
\hline $\begin{array}{c}\text { A. parasiticus + Quitosana } \\
0,5 \%\end{array}$ & $15,7 \mathrm{~B}$ & 1,8 \\
\hline A. parasiticus + Quitosana 1\% & $13,2 \mathrm{~B}$ & 0,9 \\
\hline A. parasiticus + Quitosana 2\% & $8,6 \mathrm{C}$ & 1,4 \\
\hline
\end{tabular}



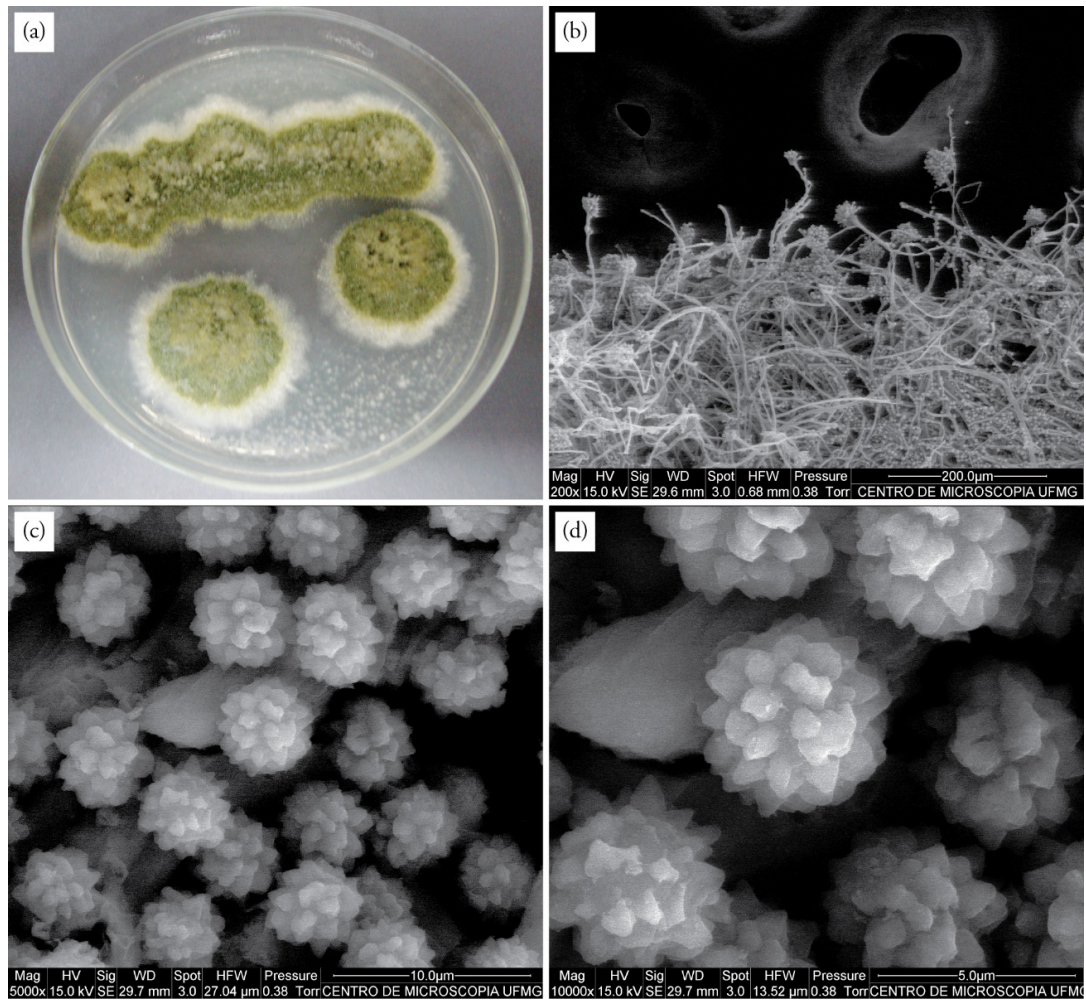

Figura 1. A. parasiticus IMI 242695 incubados em meio ágar GYEP, por 7 dias, a $25^{\circ} \mathrm{C}$. (a) Macroscopia do crescimento fúngico - controle positivo (10 $\mu \mathrm{l}$ da suspensáo de $1,0 \times 10^{6}$ esporos/ml de em cada "spot"), (b) eletromicrografia da colônia de $A$. parasiticus (aumento de $200 \mathrm{X}$ ), (c) eletromicrografia dos esporos de A. parasiticus (aumento de $5.000 \mathrm{X}$ ), (d) eletromicrografia dos conídios de A. parasiticus (aumento de $10.000 \mathrm{X}$ ).
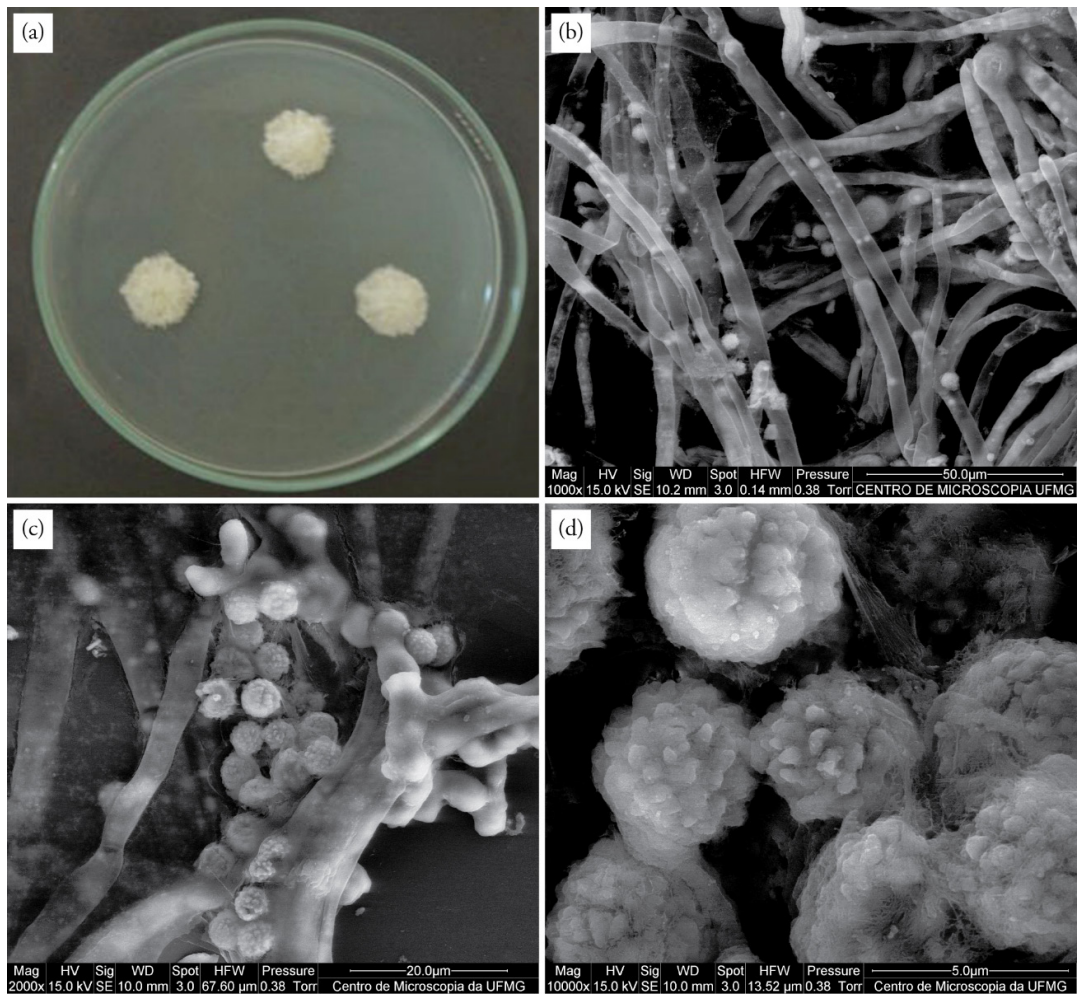

Figura 2. A. parasiticus IMI 242695 incubados em meio ágar GYEP suplementado com quitosana $0,5 \%$, por 7 dias, a $25^{\circ} \mathrm{C}$. (a) Macroscopia do crescimento fúngico $\left(10 \mu \mathrm{l}\right.$ da suspensão de $1,0 \times 10^{6}$ esporos $/ \mathrm{ml}$ de em cada "spot"), (b) eletromicrografia da colônia de $A$. parasiticus (aumento de $200 \mathrm{X}$ ), (c) eletromicrografia dos conídios de $A$. parasiticus (aumento de $5.000 \mathrm{X}$ ), (d) eletromicrografia dos conídios de A. parasiticus (aumento de $10.000 \mathrm{X}$ ). 

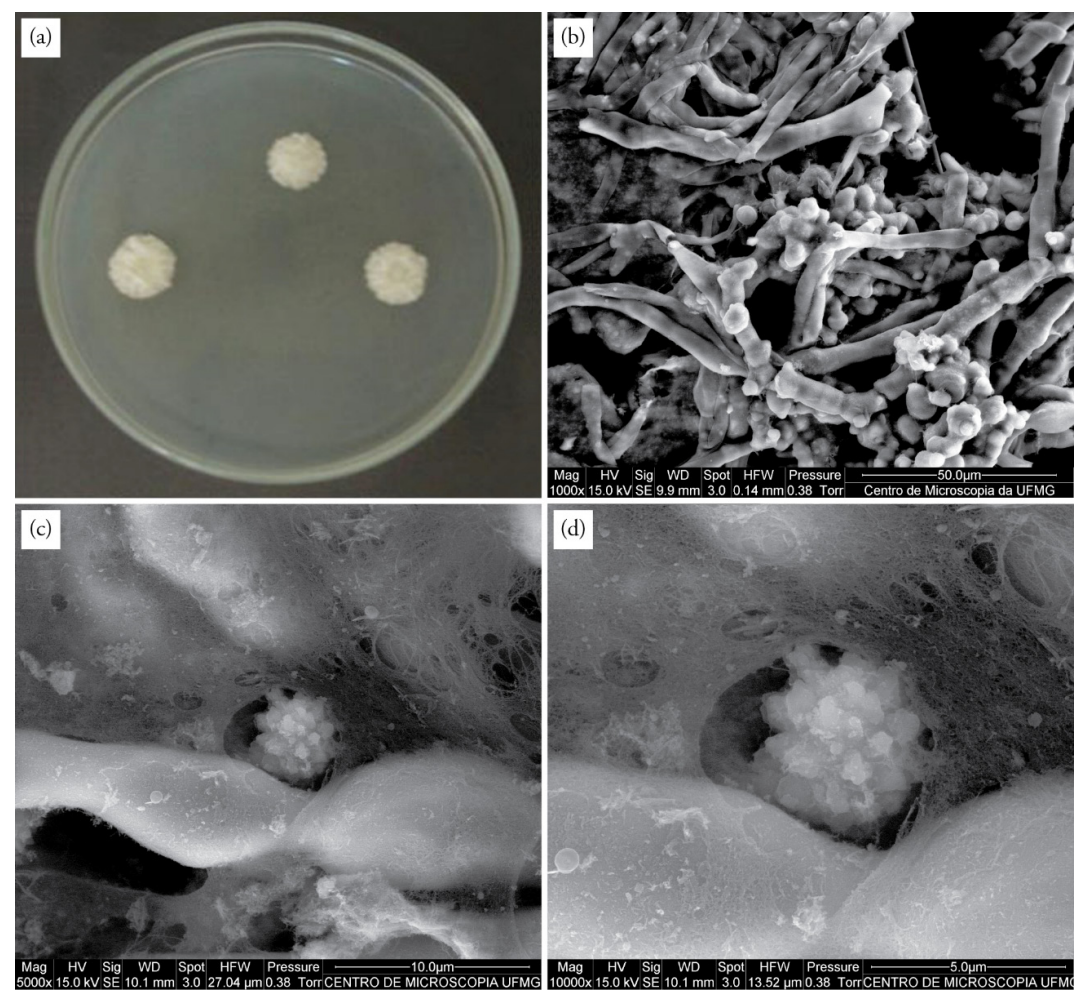

Figura 3. A. parasiticus IMI 242695 incubados em meio ágar GYEP suplementado com quitosana a $1 \%$, por 7 dias, a $25^{\circ} \mathrm{C}$. (a) Macroscopia do crescimento fúngico $\left(10 \mu \mathrm{l}\right.$ da suspensão de $1,0 \times 10^{6}$ esporos $/ \mathrm{ml}$ de em cada "spot"), (b) eletromicrografia da colônia de $A$. parasiticus (aumento de $200 \mathrm{X}$ ), (c) eletromicrografia dos conídios de $A$. parasiticus (aumento de $5.000 \mathrm{X}$ ), (d) eletromicrografia dos conídios de A. parasiticus (aumento de $10.000 \mathrm{X}$ ).
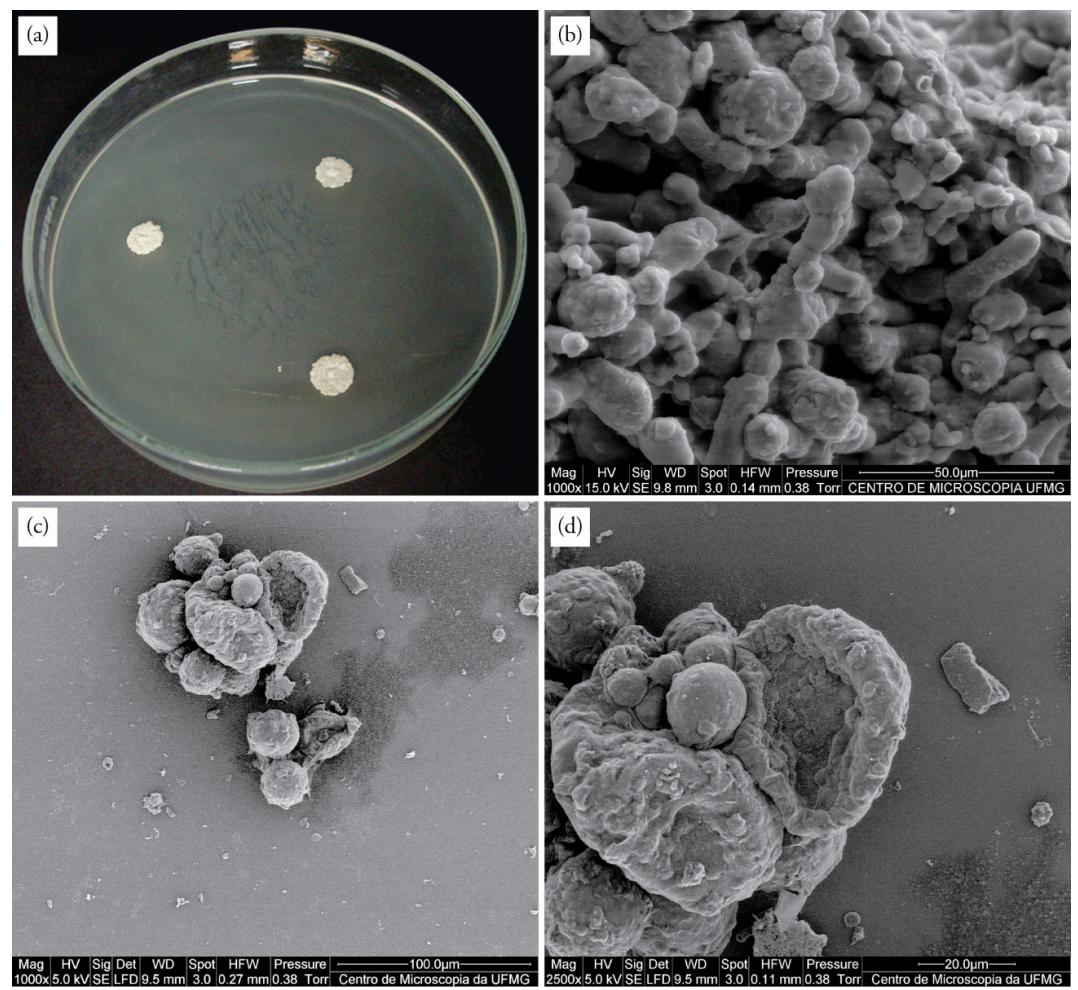

Figura 4. A. parasiticus IMI 242695 incubados em meio ágar GYEP suplementado com quitosana a $2 \%$, por 7 dias, a $25^{\circ} \mathrm{C}$. (a) Macroscopia do crescimento fúngico $\left(10 \mu \mathrm{l}\right.$ da suspensáo de $1,0 \times 10^{6}$ esporos $/ \mathrm{ml}$ de em cada "spot"), (b) eletromicrografia da colônia de $A$. parasiticus (aumento de $200 \mathrm{X}$ ), (c) eletromicrografia dos conídios de $A$. parasiticus (aumento de $5.000 \mathrm{X}$ ), (d) eletromicrografia dos conídios de A. parasiticus (aumento de $10.000 \mathrm{X}$ ). 
em suas dimensôes e forma quando comparados ao controle, permanecendo com $5 \mu \mathrm{m}$ de diâmetro, globosos, hialinos e com a presença de espículas (Figuras 1c,d, Figuras 2c,d, Figuras 3c,d e Figuras 4c,d), por outro lado, os conídios obtidos a partir do meio de cultura suplementado com quitosana a $2 \%$, mostraram-se entumecidos, apresentando $20 \mu \mathrm{m}$ de diâmetro, hialinos e com ausência de espículas (Figuras 1c,d e Figuras 4c,d).

Liu et al. (2007) obtiveram resultados semelhantes ao avaliar o efeito da quitosana, no desenvolvimento de B. cinerea e P. expansum, onde foi observada uma significativa inibição na germinação dos esporos, no alongamento do tubo germinativo e no crescimento micelial.

Maia et al. (2010) avaliaram o efeito da quitosana no desenvolvimento in vitro de plântulas de videira cv. Merlot e sua atividade antifúngica sobre Elsinoeampelina. Foi demonstrado um efeito fitotóxico nas plântulas e fungistático sobre $E$. ampelina, reduzindo o diâmetro micelial em $81,7 \%$ em relação ao controle.

El Ghaouthet al. (1992a,b) observaram que a quitosana reduziu as podridóes em morangos, causadas por $B$. cinerea e Rhizopus stolonifer, e concluíram que o mecanismo pelo qual a quitosana reduz podridóes em morangos parece estar relacionado à sua propriedade fungistática. Quando avaliada in vitro, a quitosana inibiu os dois patógenos, mas não completamente. Os autores observaram que a quitosana alterou bruscamente a morfologia das hifas de $R$. stolonifer.

Hernández-Lauzardo et al. (2008) observaram que houve um efeito inibitório sobre o crescimento micelial de $R$. stolonifer utilizando-se uma quitosana de baixo peso molecular, provocando alteraçóes na morfologia dos esporos. Coqueiro \& Di Piero, (2011), avaliaram o efeito antifúngico de quitosanas com pesos moleculares diferentes sobre Alternaria solani, causador da pinta negra em tomateiros. Os autores verificaram, em estudos in vitro, uma inibição significativa da germinação dos conídios e do crescimento micelial do fungo de $85 \%$ e $50 \%$, respectivamente, concluindo que os diferentes pesos moleculares da quitosana apresentaram efeitos similares em relação à atividade antifúngica.

Embora esses trabalhos tenham demonstrado o efeito fungistático da quitosana, o mecanismo de atuação sobre o patógeno ainda não está totalmente esclarecido. Especula-se que a natureza catiônica colabore para a atuação da quitosana, uma vez que suas cargas positivas podem interagir com os resíduos carregados negativamente das macromoléculas expostas na superfície da célula de patógenos, causando alteração na permeabilidade da membrana celular (Coqueiro \& Di Piero, 2011).

Devido aos resultados de inibição obtidos com a utilização do filme de quitosana com concentração de $2 \%$, esta concentração foi selecionada para avaliar a capacidade deste filme em reduzir a concentração de aflatoxinas produzidas por A. parasiticusnos grãos de amendoim. Com isso, verificou-se que tanto os gráos submetidos à imersão quanto os submetidos à aspersão apresentaram uma redução significativa na sua concentração de aflatoxinas quando comparados com o controle, $84,3 \%$ e $86,7 \%$ respectivamente. Foi observada interaçáo significativa entre os tipos de aplicação, indicando que o método de aplicaçáo influenciou o controle da produção de aflatoxina. A aspersão foi significativamente mais eficiente em reduzir a concentração de aflatoxinas que o método de imersão (Tabela 2).

O amendoim é muito suscetível à contaminação por fungos aflatoxigênicos, esta contaminação pode ocorrer em qualquer etapa de sua produção, principalmente no período pós-colheita. Apesar disso, ainda não está disponível um método totalmente eficaz e acessível economicamente para eliminar tal contaminação (Prado et al., 2008, 2011). Contudo, o recobrimento de alimentos com filmes comestíveis podem melhorar sua resistência a fitopatógenos por melhorar sua integridade estrutural do substrato revestido, provendo proteção física contra injúrias, e reduzindo as portas de entrada para a infecção e, por consequência, para a produção de aflatoxinas (Cabral et al., 2013; Cerqueira et al., 2011).

Filmes à base de quitosana têm sido utilizados no recobrimento de frutos e outros alimentos para conferir proteção contra a ação de patógenos, melhorar sua aparência junto ao consumidor, retardar o amadurecimento, evitar a perda de massa, reduzir a troca gasosa, preservar a coloraçáo original, induzir a resistência no vegetal e, com isso, aumentar o tempo de prateleira dos produtos (Botelho et al., 2010; Cerqueira et al., 2011; Tanada-Palmuet al., 2005).

Cia et al. (2010) verificaram que o uso da quitosana foi eficaz para reduzir a severidade e a incidência de R.stolonifer em caquis, como o processo de colonização e infecção de fitopatógenos são semelhantes em sua essência, as mesmas propriedades que impediram a infecção de $R$. stolonifer devem ter atuado sobre o $A$. parasiticus nos grãos de amendoim pesquisados no presente estudo. Além dos danos diretos causados pela ingestáo de aflatoxinas, como o câncer de

Tabela 2. Médias das aflatoxinas $\left(\mu \mathrm{g} \mathrm{kg}{ }^{-1}\right.$ ) produzidas por $A$. parasiticus em amendoins revestidos com um filme de quitosana a $2 \%$ por imersão ou aspersão, e percentual de redução de aflatoxinas em relação ao controle

\begin{tabular}{|c|c|c|c|c|}
\hline \multirow{2}{*}{ Ensaio } & \multicolumn{2}{|c|}{ Controle } & \multicolumn{2}{|c|}{ Redução (\%) } \\
\hline & Imersão & Aspersão & Imersão & Aspersão \\
\hline Controle A. parasiticus & $45.170,20 \mathrm{Aa}$ & $15.405,20 \mathrm{Ab}$ & - & - \\
\hline A. parasiticus + Quitosana $2 \%$ & $7.093,60 \mathrm{Ba}$ & $2.049,80 \mathrm{Bb}$ & 84,3 & 86,7 \\
\hline
\end{tabular}

$\mathrm{Na}$ linha, as médias seguidas pela mesma letra minúscula, e na coluna, pela mesma letra maiúscula, não diferem entre si, pelo teste Tukey ( $<<0,05)$. 
fígado, essas micotoxinas influenciam negativamente os prognósticos de 6 dos 10 agravos à saúde humana mais importantes indicados pela organização mundial da saúde (Oliveira et al., 2004; Williams et al., 2004).

Como os agravos à saúde produzidos pela aflatoxinas são dose dependente, qualquer método ou técnica que elimine ou reduza a concentração dessa substância nos alimentos poderá reduzir de forma direta seus efeitos no organismo. Os resultados obtidos neste estudo confirmam o efeito antifúngico da quitosana e demonstraram a viabilidade de utilização de um filme comestível à base dessa substância como uma importante ferramenta para o controle de aflatoxicoses.

\section{CONCLUSÃO}

A quitosana foi capaz de inibir o crescimento do micélio e de induzir alteraçôes morfológicas nos esporos de $A$. parasiticus in vitro. O filme de quitosana a $2 \%$ inoculado pela metodologia de aspersão foi mais eficiente que o método de imersão, no controle da produçấo de aflatoxinas em amendoins. Sendo assim, concluímos que um filme de quitosana a $2 \%$ pode ser utilizado para o controle do crescimento micelial e na reduçấo da concentração de aflatoxinas produzidas por A. parasiticus, em amendoim. Tal propriedade confere a essa substância uma grande perspectiva de utilização no controle de fungos aflatoxigênicos em alimentos.

\section{AGRADECIMENTOS}

Os autores agradecem ao $\mathrm{CNPq}$ (Conselho Nacional de Desenvolvimento Científico e Tecnológico) e à FAPEMIG (Fundação de Amparo à Pesquisa de Minas Gerais) pelo suporte financeiro.

\section{REFERÊNCIAS}

Botelho, R. V., Maia, A. J., Rickli, E. H., Leite, C. D., \& Faria, C. M. D. R. (2010). Quitosana no controle de Penicillium sp na póscolheita de maçâs. Revista Brasileira de Agroecologia, 5, 200-206.

Cabral, L. C., Fernández Pinto, V., \& Patriarca, A. (2013). Application of plant derived compounds to control fungal spoilage and mycotoxin production in foods. International Journal of Food Microbiology, 166, 1-14. http://dx.doi.org/10.1016/j.ijfoodmicro.2013.05.026. PMid:23816820.

Campana-Filho, S. P., Britto, D., Curti, E., Abreu, F. R., Cardoso, M. B., Battisti, M. V., Sim, P. C., Goy, R. C., Signini, R., \& Lavall, R. L. (2007). Extração, estruturas e propriedades de $\alpha$ - e $\beta$-quitina. Quimica Nova, 30, 644-650. http://dx.doi.org/10.1590/S010040422007000300026.
Cerqueira, T. S., Jacomino, A. P., Sasaki, F. F., \& Alleoni, A. C. C. (2011). Recobrimento de goiabas com filmes proteicos e de quitosana. Bragantia, 70, 216-221. http://dx.doi.org/10.1590/S000687052011000100028 .

Cia, P., Benato, E. A., Pascholati, S. F., \& Garcia, E. O. (2010). Quitosana no controle pós-colheita da podridão mole em caqui 'rama forte'. Bragantia, 69, 745-752. http://dx.doi.org/10.1590/ S0006-87052010000300028.

Coqueiro, D. S. O., \& Di Piero, R. M. (2011). Atividade de quitosanas com diferentes pesos moleculares sobre alternaria solani. Arquivos do Instituto Biologico, 78, 459-463.

El Ghaouth, A., Arul, J., Asselin, A., \& Benhamou, N. (1992a). Antifungal activity of chitosan on post-harvest pathogens: induction of morphological and cytological alterations in Rhizopus stolonifer. Mycological Research, 96, 769-779. http://dx.doi.org/10.1016/ S0953-7562(09)80447-4.

El Ghaouth, A., Arul, J., Grenier, J., \& Asselin, A. (1992b). Antifungal activity of chitosan on two post-harvest pathogens of strawberry fruits. Phytopathology, 82, 398-402. http://dx.doi.org/10.1094/Phyto-82-398.

Hernández-Lauzardo, A. N., Bautista-Baños, S., Velázquez-Del Valle, M. G., Méndez-Montealvo, M. G., Sánchez-Rivera, M. M., \& Bello-Pérez, L. A. (2008). Antifungal effects of chitosan with different molecular weights on in vitro development of Rhizopus stolonifer (Ehrenb.:Fr.) Vuill. Carbohydrate Polymers, 73, 541-547. http://dx.doi.org/10.1016/j.carbpol.2007.12.020. PMid:26048219.

Klich, M. A. (2007). Environmental and developmental factors influencing aflatoxin production by Aspergillus flavus and Aspergillus parasiticus. Mycoscience, 48, 71-80. http://dx.doi.org/10.1007/ S10267-006-0336-2.

Liu, L., Tian, S., Meng, X. G., \& Xu, Y. (2007). Effects of chitosan on control of post-harvest diseases and physiological responses of tomato fruits. Postharvest Biology and Technology, 44, 300-306. http://dx.doi.org/10.1016/j.postharvbio.2006.12.019.

Maia, A. J., Leite, C. D., Botelho, R. V., Faria, C. M. D. R., \& Uber, S. C. (2010). Efeitos da quitosana no desenvolvimento in vitro de videiras cv. Merlot e no crescimento micelial do fungo Elsinoeampelina. Ciência e Agrotecnologia, 34, 1425-1430. http://dx.doi.org/10.1590/ S1413-70542010000600010.

Mali, S., Grossmann, M. V. E., \& Yamashita, F. (2010). Filmes de amido: produção, propriedades e potencial de utilizaçáo. Semina. Ciências Agrárias, 31, 137-156. http://dx.doi.org/10.5433/16790359.2010v31n $1 \mathrm{p} 137$.

Moura, C., Muszinski, P., Schmidt, C., Almeida, J., \& Pinto, L. (2006). Quitina e quitosana produzidas a partir de resíduos de camarão e siri: avaliação do processo em escala piloto. Vetor, 16, 37-45.

Oliveira, C. A. F., Butkeraitis, P., Rosmaninho, J. F., Guerra, J. L., Correa, B., \& Reis, T. A. (2004). Alteraçóes hepáticas em codornas japonesas submetidas à intoxicaçáo prolongada por aflatoxina B1. Ciência Rural, 34, 213-217. http://dx.doi.org/10.1590/S010384782004000100033.

Prado, G., Madeira, J. E. G. C., Morais, V. A. D., Oliveira, M. S., Souza, R. A., Peluzio, J. M., Godoy, I. J., Silva, J. F., \& Pimenta, R. S. (2011). Reduction of aflatoxin B1 in stored peanuts (Arachis hypogaea 
L.) using Saccharomyces cerevisiae. Journal of Food Protection, 74, 1003-1006. http://dx.doi.org/10.4315/0362-028X.JFP-10-380. PMid:21669081.

Prado, G., Souza, R. A., Morais, V. A. D., Madeira, J. E. G. C., Oliveira, M. S., Andrade, M. C., Godoy, I. J., Rosa, C. A., Corrêa, A., Jr., Peluzio, J. M., \& Pimenta, R. S. (2008). Influência de Saccharomycopsis schoenii e Saccharomycopsis crataegensis na produção de aflatoxinas B1 e G1 por Aspergillus parasiticus em amendoim (Arachis hypogaea L.). Revista do Instituto Adolfo Lutz, 67, 177-182.

Tanada-Palmu, P. S., Proença, P. S. P., Trani, P. E., Passos, F. A., \& Grosso, C. R. F. (2005). Recobrimento de sementes de brócolos e salsa com coberturas e filmes biodegradáveis. Bragantia, 64, 291-297. http://dx.doi.org/10.1590/S0006-87052005000200016.
Valente Soares, L. M., \& Rodriguez-Amaya, D. B. (1989). Survey of aflatoxins, ochratoxin A, zearalenone, and sterigmatocystin in some Brazilian foods by using multi-toxin thin-layer chromatographic method. Journal Association of Official Analytical Chemists, 73, 22-26. PMID: 2523887.

Viegas, E. C., \& Rossetto, C. A. V. (2006). Contaminação por Aspergillus spp.emArachis hypogaea. RevistaAgronomia, 40, 73-82.

Williams, J. H., Phillips, T. D., Jolly, P. E., Stiles, J. K., Jolly, C. M., \& Aggarwal, D. (2004). Human aflatoxicosis in developing countries: a review of toxicology, exposure, potential health consequences, and interventions. The American Journal of Clinical Nutrition, 80, 11061122. PMid: 15531656. 